\title{
ANALISIS DAMPAK LALU LINTAS PEMBANGUNAN HOTEL FRONT ONE TULUNGAGUNG KABUPATEN TULUNGAGUNG
}

\author{
Tiok Kresna Aji *1, Sigit Winarto ${ }^{2}$, Ahmad Ridwan ${ }^{3}$, Agata Iwan Candra ${ }^{4}$. \\ 1,2,3 Fakultas Teknik, Universitas Kadiri. \\ e-mail:*1 tiokkresna1@gmail.com, 2 sigit.winarto@unik-kediri.ac.id, \\ 3 ahmad_ridwan@unik-kediri.ac.id, ${ }^{4}$ iwan_candra@unik-kediri.ac.id.
}

\begin{abstract}
This research was carried out against the background of the pattern of development progress in Tulungagung District so quickly that it affected the transportation sector. Transportation has an important role, which is to support the mobility of people and goods as well as for the implementation of intra and intermodal integration in order to remain smooth and orderly. But it not only the traffic system that needs attention, the facilities and infrastructure, namely the construction the Front One Hotel, which is the center of community activities, which is a gathering place for people to rest/spend the night and carry out celebrations or meetings as well as their impact. This research was conducted in the construction area of the Tulungagung Front One Hotel. The purpose of this study was to determine the impact of traffic development in the Front One Tulungagung Hotel. The analysis of the research uses the method described in the 1997 Indonesian Road Capacity Manual. The results of the analysis of this study are that the construction of Front One is expected to attract and generate new trips, affect the Level of Service (LOS) and affect the intersection of the SimpangEmpatPlandaan.
\end{abstract}

Keywords: $\quad$ Traffic Impact, Level Of Service (LOS), Parking, Pull, Reliable

\begin{abstract}
Abstrak
Penelitian ini dilakukan dengan latar belakang pola kemajuan perkembangan pembangunan yang ada di Kabupaten Tulungagung begitu cepat sehingga mempengaruhi sektor transportasi. Transportasi memiliki peranan yang penting yaitu menunjang mobilitas orang maupun barang serta untuk terlaksananya keterpaduan intra dan antar moda agar tetap lancar dan tertib di wilayah Kabupaten Tulungagung, maka dibutuhkan suatu sistem jaringan lalu lintas yang lancar, aman, hemat waktu dan efesien. Namun bukan hanya sistem lalu lintas yang perlu diperhatikan, sarana dan prasarana yaitu pembangunan Hotel Front One yang menjadi pusat kegiatan masyarakat, yang merupakan tempat berkumpulnya orang untuk beristirahat / bermalam maupun melaksanakan acara hajatan ataupun acara pertemuan juga perlu diperhatikan dampaknya. Penelitian ini dilakukan di wilayah pembangunan Hotel Front One Tulungagung. Tujuan penelitian ini adalah untuk mengetahui dampak lalu lintas pembangunan Hotel Front One Tulungagung. Analisis penelitian menggunakan metode yang telah dijelaskan dalam Manual Kapasitas Jalan Indonesia Tahun 1997. Hasil analisis dari penelitian ini adalah pembangunan Front One diperkirakan akan menarik dan membangkitkan perjalanan baru, mempengaruhi Level Of Service (LOS) dan mempengaruhi persimpangan Simpang Empat Plandaan.
\end{abstract}

Kata Kunci : $\quad$ Dampak Lalu Lintas, Bangkitan, Level Of Service (LOS), Parkir, Tarikan 


\section{PENDAHULUAN}

Transportasi adalah sarana yang sangat penting dalam menunjang pertumbuhan dan pembangunan di suatu daerah, memperlancar roda perekonomian, memperkokoh persatuan dan kesatuan serta mempengaruhi semua aspek kehidupan [1][2]. Sistem lalu lintas pada dasarnya berupa sistem jaringan yang terdiri dari ruas dan simpul [3][4]. Hotel Front One Tulungagung merupakan lokasi dalam sistem jaringan transportasi yang berfungsi pokok seperti penataan sirkulasi lalu lintas pada areal ini dapat dipastikan menimbulkan dampak yang cukup signifikan terhadap perubahan pola lalu lintas pada wilayah tersebut. Analisis yang dimaksud Menurut Pedoman Analisa Dampak Lalu Lintas jalan Akibat Pengembangan Kawasan Perkotaa, Departemen Pekerjaan Umum 2009 seperti yang dikutip dalam [5][6][7] Analisis dampak lalu lintas adalah suatu studi khusus yang di lakukan untuk menilai pengaruh yang dapat mengakibatkan perubahan tingkat pelayanan pada ruas dan atau persimpangan jalan yang diakibatkan oleh lalu lintas jalan yang di bangkitkan suatu kegiatan dan atau usaha pada suatu kawasan tertentu"

Rencana pembangunan Hotel Front One Tulungagung tentunya akan mengakibatkan tarikan maupun bangkitan yang tinggi, maka diperlukan suatu Study Analisa Dampak Lalu Lintas terhadap unjuk kerja jaringan jalan dengan beroperasinya hotel tersebut serta menganalisa kinerja jaringan jalan maupun upaya manajemen dan rekayasa lalu lintas baik daerah sekitar lokasi, sehingga nantinya dampak - dampak yang diperkirakan timbul akan dapat diminimalisir [8][9].

Identifikasi masalah yang terjadi adalah manajemen pembangunan Hotel Front One Tulungagung yang tidak tepat dapat menimbulkan dampak antara lain:Timbulnya titik-titik kemacetan lalu lintas terutama disekitar aksesibilitas kawasan tersebut.Munculnya parkir liar dipinggir jalan yang digunakan oleh masyarakat yang akanke hotel yang lokasinya berada di Jalan Antasari.Terjadinya kesemrawutan dan kemacetan lalu lintasdi persimpangan ber APILL yang berada di dekat kawasan Hotel Front One, yang berimbas pada keborosan waktu dan antrian kendaraan di persimpangan tersebut.Dampak lain yang ditimbulkan adalah dampak lingkungan dan sosial pada masyarakat di sekitar hotel utamanya tingginya pencemaran lingkungan, maupun kemungkinan terjadinya kecelakaan.

Sesuai dengan latar belakang dan identifikasi masalah tersebut diatas, maka dapat diangkat rumusan masalah sebagai berikut :

a. Bagaimana perkiraan besarnya tarikan dan bangkitan akibat Pembangungan Hotel Front One Tulungagung?

b. Bagaimana Identifikasi kinerja lalu lintas diwilayah sekitar Pembangungan Hotel Front One Tulungagung di tahun penelitian dan tahun rencana? 
c. Bagaimana perkiraan dampak dan menata yang diakibatkan dari Pembangungan Hotel Front One Tulungagung ?

Penelitian ini bertujuan untuk mengetahui ruas dan persimpangan yang diperkirakan terkena dampak akibat kegiatan Pembangungan Hotel Front One Tulungagung. Tujuan didasarkan pada kondisi eksisting dan kondisi pada tahun rencana. Secara lebih rinci tujuan penelitian ini dapat dijelaskan sebagai berikut :

a. Untuk memperkirakanbesarnyatarikandanbangkitanakibatPembangungan Hotel Front One Tulungagung.

b. Untuk mengidentifikasikinerjalalulintas di wilayahPembangungan Hotel Front One Tulungagung di tahunpenelitiandantahunrencana.

c. Untuk memperkirakandampak yang diakibatkandariPembangungan Hotel Front One Tulungagung.

d. Untuk menata danmenghitungkebutuhantempatparkirpadaPembangungan Hotel Front One Tulungagung.

Andalalin merupakan serangkaian kegiatan kajian mengenai dampak lalu lintas dari pembangunan pusat kegiatan, pemukiman, dan infrastruktur yang hasilnya di tuangkan dalam bentuk dokumen hasil analisis dampak lalu lintas [10][11]. Study iniadalahsolusi yang dapat memecahkan masalah akibat beroperasinya Hotel Front One Tulungagung hingga tahun 2024. Dengan demikian, peneliti merekomendasikan hasil study sebagai acuan bagi Pemerintah Kabupaten Tulungagung melalui instansi terkait untuk mengatasi dampak lalu lintas jangka pendek yang dimungkinkan timbul.

\section{METODE PENELITIAN}

\subsection{Lokasi Penelitian.}

Penelitian ini dilakukan di Kabupaten Tulungagung tepatnya di Jalan Antasari desa Tanon, Kecamatan Kedungwaru, Kabupaten Tulungagung..

\subsection{Data dan Metode Penelitian}

Penelitian ini menggunakan dua data, yaitu data sekunder dan data primer [12][13]. Data sekunder penelitian ini merupakan usulan gambar pembangunan Hotel Front One Tulungagung, data jaringan jalan serta data tata guna lahan sekitar daerah pembangunan serta tata guna lahan Kabupaten Tulungagung, sedanglan data primer penelitian ini adalah hasil survey Inventarisasi Jaringan Jalan (Road and Traffic Control Devices Inventories), Inventarisasi Geometrik Persimpangan (Junction Geometric Inventory), serta Inventarisasi Pengaturan persimpangan (Junction Plan Inventory) "'[14][15]. Untuk Pencacahan Lalu Lintas meliputi Survey Pencacahan 
lalu lintas terklasifikasi (Classified Traffic Counting) serta Pencacahan Lalu Lintas Membelok (Classified Turning Movement Count). Sedangkan untuk kelompok Tarikan Perjalanan dilakukan dengan menghitung jumlah keluar masuk kendaraan dalam satuan kendaraan/jam [16][17]. Metode yang digunakan meliputi kelompok Inventarisasi (Inventory Survey), kelompok Pencacahan Lalu Lintas (Traffic Counting Survey), dan kelompok Tarikan Perjalanan (Trips Attraction Survey). Sedangkan metode dilakukan dengan penghitungan, pengukuran (walking measures/whell-meter), pencatatan secara manual, dan wawancara kepada responden[18].

Tabel 1. Jenis dan Metoda Survei Pekerjaan Analisis Dampak Lalu Lintas Hotel Front One Tulungagung

\begin{tabular}{|c|c|c|c|}
\hline No & Jenis & Metode & $\begin{array}{r}\text { Lama } \\
\text { Waktu } \\
\end{array}$ \\
\hline 1 & \multicolumn{3}{|l|}{ Inventory Surveys } \\
\hline & Roadway Inventory & $\begin{array}{l}\text { Pengukuran dengan theodolit dan } \\
\text { pencatatan }\end{array}$ & 1 hari \\
\hline & Intersection Inventory & $\begin{array}{l}\text { Pengukuran dengan theodolit dan } \\
\text { pencatatan }\end{array}$ & 1 hari \\
\hline \multirow[t]{2}{*}{2} & \multicolumn{3}{|c|}{ Traffic Counting Surveys } \\
\hline & $\begin{array}{l}\text { Classified Turning } \\
\text { Movement Count }\end{array}$ & $\begin{array}{l}\text { Penghitungan manual dan pencatatan } \\
\text { dengan turus/tally }\end{array}$ & 14 jam \\
\hline \multicolumn{2}{|c|}{ Classified Traffic Counting } & $\begin{array}{l}\text { Penghitungan manual dan pencatatan } \\
\text { dengan turus/tally }\end{array}$ & 7 jam \\
\hline \multicolumn{4}{|c|}{ Trip Attraction Survey } \\
\hline \multicolumn{2}{|c|}{ Lisence Plat Survey } & $\begin{array}{l}\text { Pencatatan nomor plat kendaraan di pintu } \\
\text { keluar masuk objek pembanding }\end{array}$ & $\begin{array}{c}14 \\
\text { jam } \\
\end{array}$ \\
\hline \multicolumn{2}{|c|}{ Trip Attraction Survey } & $\begin{array}{l}\text { Pencatatan nomor plat kendaraan di pintu } \\
\text { keluar masuk objek pembanding }\end{array}$ & $\begin{array}{c}7 \\
\text { jam } \\
\end{array}$ \\
\hline
\end{tabular}

Sumber : Pengamatan

\subsection{Pengembangan Model}

Penyusun menggunakan pembebanan lalu lintas secara manual. Model transportasi ini akan memberikan suatu gambaran lalu lintas pada daerah yang di studi. Menurut [19] hubungan antara lalu lintas dengan tata guna lahan dapat dikembangkan melalui suatu proses perencanaantransportasi yang saling terkait, terdiri atas :Bangkitan / tarikan perjalanan. Penyebaran perjalanan. Pembebanan lalu lintas. Pemilihan moda. 


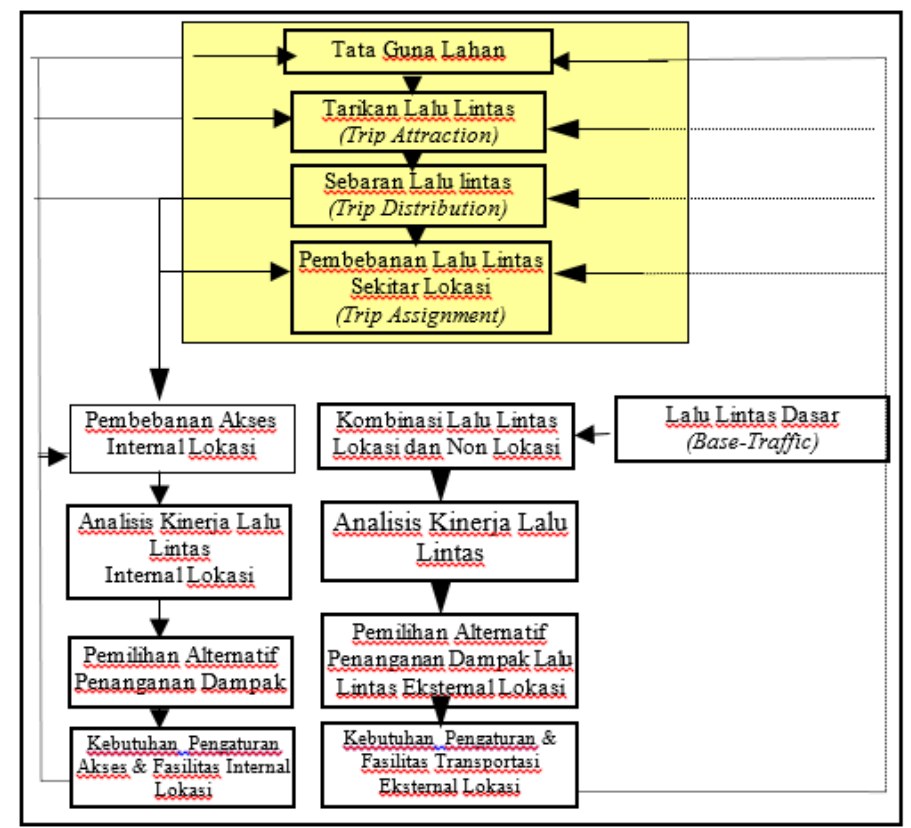

Sumber : Analisa Pengamatan

Gambar 1. Pola Pikir Pemodelan Analisis Dampak Lalu Lintas

\section{HASIL DAN PEMBAHASAN}

\subsection{Tarikan Perjalanan (Trip Attraction Survey)}

Bangkitan/tarikan pergerakan adalah tahapan pemodelan yang memperkirakan jumlah pergerakan yang berasal dari suatu zona atau lahan dan jumlah pergerakan yang tertarik ke suatu tata guna lahan atau zona. Pembangunan Hotel Front One di JL. Antasari diperkirakan akan menarik perjalanan baru sebesar 14,73 smp/jam dan membangkitkan perjalanan baru sebesar 16,11 smp/jam. Pada saat hari libur (weekend) Tarikan perjalanan tersebut diprediksikan naik sebesar 16,62 smp/jam dan Bangkitan perjalanan sebesar21.79 smp/jam. Menurut [20] Volume lalu lintas adalah banyaknya kendaraan yang melewati suatu titik pengamatan dalam satuan waktu (hari, jam, menit). Satuan volume lalu lintas umumnya dipergunakan sehubungan dengan penentuan jumlah dan lebar lajur adalah : Lalu Lintas Harian Rata-rata, Volume jam perencanaan, dan Kapasitas

\subsection{Pelayanan Ruas Jalan (Level Of Service / LOS)}


Tingkat pelayanan adalah suatu metode untuk memberikan batasan-batasan ukuran untuk dapat menjawab pertanyaan apakah kondisi suatu ruas jalan yang ada saat ini masih memenuhi syarat untuk di lalui oleh volume maksimum saat ini maupun peningkatan hingga yang akan datang Berdasarkan hasil survey, kondisi ruas jalan di sekitar Hotel sebelum beroperasi mempunyai V/C Ratio sebagai berikut :

Tabel 2 Kinerja Lalu Lintas

\begin{tabular}{c|l|c|c|c}
\hline No & \multicolumn{1}{|c|}{ Nama Jalan } & Volume & Kapasitas & VC Ratio \\
\hline 1 & Jl. Antasari & 1669,0 & 3595,4 & 0,46 \\
\hline 2 & Jl. Kapten Kasihin & 2621,6 & 3434,3 & 0,76 \\
\hline 3 & Jl. Adi Sucipto & 1419,4 & 3373,0 & 0,42 \\
\hline 4 & Jl. Agus Salim & 1967,4 & 3430,7 & 0,57 \\
\hline
\end{tabular}

Sumber : Analisa Pengamatan

Untuk kerja jaringan jalan pada sekitar lokasi dapat di lihat berdasarkan tingkat pelayanan pada jalan tersebut. Adapun tingkat pelayanan di sekitar objek sebagai mana tabel berikut :

Tabel 3 Tingkat Pelayanan Lalu Lintas

\begin{tabular}{c|l|c|c}
\hline No & \multicolumn{1}{|c|}{ Nama Jalan } & VC (smp/jam) & Level of Service \\
\hline 1 & Jl. Antasari & 0,46 & $\mathrm{C}$ \\
\hline 2 & Jl. Kapten Kasihin & 0,76 & $\mathrm{D}$ \\
\hline 3 & Jl. Adi Sucipto & 0,42 & $\mathrm{~B}$ \\
\hline 4 & Jl. Agus Salim & 0,57 & $\mathrm{C}$ \\
\hline
\end{tabular}

Sumber : Analisa Pengamatan

Penetuan tingkat pelayanan ruas jalan (Level of Service /LOS) berdasarkan Peraturan Menteri Perhubungan Nomor PM 96 Tahun 2015 tentang Pedoman Pelaksanaan Kegiatan Manajemen Dan Rekayasa Lalu Lintas. Ruas jalan di sekitar lokasi pembangunan tingkat pelayanannya berada pada level C yang artinya Arus stabil, tetapi kecepatan dan gerak kendaraan dikendalikan. Pengemudi dibatasi dalam memilih kecepatan.

\subsection{Dampak terhadap unjuk kerja persimpangan}

Dengan beroperasinya Hotel Front One diprediksikan akan menimbulkan dampak terhadap unjuk kerja Persimpangan di sekitar lokasi tersebut. Persimpangan yang secara langsung berdampak adalah Simpang Empat Plandaan.

Tabel 4. Kinerja Simpang Empat Plandaan

\begin{tabular}{l|l|c|c|c|c}
\hline No & Pendekat & $\begin{array}{c}\text { Derajad } \\
\text { Jenuh (DS) }\end{array}$ & $\begin{array}{c}\text { Tundaan } \\
\text { Rata-rata } \\
(\text { detik/smp) }\end{array}$ & $\begin{array}{c}\text { Tundaan } \\
\text { Simpang } \\
\text { (detik) }\end{array}$ & LOS \\
\hline
\end{tabular}




\begin{tabular}{|c|c|c|c|c|c|}
\hline 1 & Timur (Jl. Hasanudin) & 0,56 & 32,98 & \multirow{4}{*}{32,23} & \multirow{4}{*}{$\mathrm{D}$} \\
\hline 2 & $\begin{array}{l}\text { Barat (Jl. Kapten } \\
\text { Kasihin) }\end{array}$ & 0,56 & 26,17 & & \\
\hline 3 & $\begin{array}{l}\text { Utara (Jl. Sultan } \\
\text { Agung) }\end{array}$ & 0,56 & 25,65 & & \\
\hline 4 & Selatan (Jl. Antasari) & 0,56 & 34,58 & & \\
\hline
\end{tabular}

Berdasarkan tabel diatas tingkat pelayanan Simpang Empat Plandaan pada kondisi eksisting berada pada level D. Tingkat pelayanan pada level D ditandai dengan waktu tundaan simpang antara $25 \mathrm{detik} /$ kendaraan - $40 \mathrm{detik} /$ kendaraan.

Prediksi arus lalu lintas di sekitar lokasi Hotel Front One pada tahun 2019 setelah beroperasi dapat dilihat pada tabel berikut :

Tabel 5 Prediksi Kinerja Lalu Lintas Tahun 2019 Setelah Beroperasi

\begin{tabular}{l|l|l|c|c|c}
\hline No & \multicolumn{1}{|c|}{ Nama Jalan } & Volume & Kapasitas & VC Ratio & LOS \\
\hline 1 & Jl. Antasari & 1685,1 & 3595,4 & 0,47 & $\mathrm{C}$ \\
\hline 2 & Jl. Kapten Kasihin & 2637,7 & 3434,3 & 0,77 & $\mathrm{D}$ \\
\hline 3 & Jl. Adi Sucipto & 1435,5 & 3373 & 0,43 & $\mathrm{~B}$ \\
\hline 4 & Jl. Agus Salim & 1983,5 & 3430,7 & 0,58 & $\mathrm{C}$ \\
\hline
\end{tabular}

Sumber : Analisa Pengamatan

Berdasarkan besaran dari VC Ratio, ruas Jalan Antasari di prediksi mengalami penurunan kinerja dari semula mempunyai VC ratio sebesar 0,46 menjadi 0,47 . Kondisi ini diperlukan penanganan dikarenakan arus mendekati tidak stabil, kecepatan masih dikendalikan, V/C masih dapat ditolerir dengan kata lain pada ruas jalan tersebut terdapat tundaan lalu lintas.

Sedangkan prediksi arus lalu lintas di sekitar lokasi Hotel Front One pada tahun mendatang 2024 dapat diprediksikan besaran V/C ratio yang dapat dilihat pada tabel berikut :

Tabel 6 Prediksi Kinerja Lalu Lintas Tahun 2024

\begin{tabular}{l|l|l|c|c|c}
\hline No & \multicolumn{1}{|c|}{ Nama Jalan } & Volume & Kapasitas & VC Ratio & LOS \\
\hline 1 & Jl. Antasari & 1925,2 & 3595,4 & 0,54 & $\mathrm{C}$ \\
\hline 2 & Jl. Kapten Kasihin & 3013,6 & 3434,3 & 0,88 & $\mathrm{E}$ \\
\hline 3 & Jl. Adi Sucipto & 1640,1 & 3373 & 0,49 & $\mathrm{C}$ \\
\hline 4 & Jl. Agus Salim & 2247,7 & 3430,7 & 0,66 & $\mathrm{D}$ \\
\hline
\end{tabular}

Sumber : Analisa Pengamatan

Pada tahunvmendatang di prediksikan tingkat pelayanan pada ruas jalan di sekitar lokasi mengalami penurunan. Hal ini dapat di lihat peningkatan dari VC ratio pada Jalan Antasari dari semula $0.46 \mathrm{smp} / \mathrm{jam}$ menjadi $0.54 \mathrm{smp} / \mathrm{jam}$. Tingkat pelayanan jalan pada ruas jalan Antasari berada pada level $\mathrm{C}$. 
Tingkat pelayanan $\mathrm{C}$ mempunyai ketentuan sebagai berikut :

a. Arus stabil tetapi pergerakan kendaraan dikendalikan oleh volume lalulintas yang lebih tinggi dengan kecepatan sekurang kurangnya 60 km/jam.

b. Kepadatan lalu lintas sedang karena hambatan internal lalu lintas meningkat.

c. Pengemudi memiliki keterbatasan untuk memilih kecepatan, pindah jalur atau mendahului.

\subsection{Luasan Area Parkir}

Fasilitas parkir adalah lokasi yang ditentukan sebagai tempat pemberhentian kendaraan yang bersifat sementara untuk melakukan kegiatan pada suatu kurun waktu[21]. Pihak pengembang Hotel dimaksud harus menyediakan luasan areal parkir yang harus disesuaikan dengan kebutuhan.Sesuai standar pedoman perencanaan fasilitas parkir yang dikeluarkan oleh Kementerian Perhubungan bahwa untuk Hotel dibutuhkan ruang parkir antara 0,2 sampai dengan 1 dari SRP/Kamar. Dengan asumsi penentuan satuan ruang parkir untuk Sepeda Motor yaitu 0,75 x 2,00 meter, maka untuk Hotel Front One yang direncanakan mempunyai kamar sejumlah 40 harus menyediakan areal parkir minimal untuk sepeda motor sebesar $12 \mathrm{~m}^{2}$.

Sedangkan asumsi penentuan satuan parkir untuk mobil yaitu 3,00 x 5,00 meter, maka untuk Hotel Front One harus menyediakan areal parkir sebesar $600 \mathrm{~m}^{2}$.

\section{KESIMPULAN}

Kesimpulan dari penelitian ini adalah kondisi ruas jalan mempunyai nilai Level of Service (LOS) tergolong dalam kategori C. Selain itu berdampak juga pada kinerja ruas jalan raya Antasari yang mengalami penurunan nilai Level of Service namun masih dapat dikendalikan. Dampak yang lain adalah menimbulkan dampak terhadap persimpangan Simpang Empat Plandaan, berdasarkan VC Ratio, kondisi ini perlu diperlukan penanganan dikarenakan arus mendekati tidak stabil. Penambahan area parkir juga diperlukan sesuai dengan standart pedoman perencanaan fasilitas parker yaitu parkir antara 0,2 sampai dengan 1 dari SRP/kamar dengan asumsi untuk sepeda motor $0,75 \times 2,00$ meter dan mobil 3,00 x 5,00 meter maka harus menyediakan tempat parkir sebesar $600 \mathrm{~m}^{2}$.

\section{SARAN}

Kegiatan manajemen lalu lintas merupakan kewajiban pengembang dalam melaksanakan pembangunan hoteltersebut. Upaya rekayasa lalu lintas ini tetap harus di dasarkan kepada kebutuhan pengguna jalan sehingga kondisi lalu lintas di lokasi pembangunan tetap aman dan lancar .Beberapa saran yang dapat dilaksanakan oleh Hotel Front OneTulungagung untuk 
mengantisipasi terjadinya permasalahan lalu lintas di sekitar lokasi pembangunan adalah sebagai berikut : Melakukan penataan desain geometrik radius belok kendaraan di pintumasuk / pintukeluar. Penyediaan areal Parkir minimal sebesar $12 \mathrm{~m}^{2}$ untuk sepeda motor dan600 $\mathrm{m}^{2}$ untuk parker kendaraan roda empat, sehingga diharapkan parkir off street (parkir di luar badan jalan) yang berada di dalam area hotel kebutuhan parkirnya terlayani sesuai dengan kebutuhan pengunjung. Tidak membangun pagar yang tinggi di dekat pintu masuk maupun pintu keluar kantor. Melakukan penataan sirkulasi lalu lintas di dalam kawasan Hotel Front One. Pemasangan rambu larangan parkir. Pemasangan rambu petunjuk arah masuk kendaraan. Memasang rambu larangan masuk. Pemasangan rambu petunjuk parkir. Pemasangan rambu lokasi penginapan. Perkerasan fasilitas pejalan kaki (trotoar). Pemotongan pohon.

\section{UCAPAN TERIMAKASIH}

Dalam penyusunan artikel ini, penulis ucapkan terimakasih kepada dosen pembimbing dan Universitas Kadiri. Penulis berharap agar artikel ini dapat bermanfaat bagi pembaca.

\section{DAFTAR PUSTAKA}

[1] P. Soedarto and S. H. Tembalang, "Jurnal Teknik Sipil Universitas Diponegoro, Juni 2012 EVALUASI DAN PERENCANAAN SISTEM FEEDER JALAN Jurnal Teknik Sipil Universitas Diponegoro , Juni 2012,” no. 14, pp. 1-10, 2012.

[2] Alhani, K. Erwan, and E. Sulandari, "Analisa Lalu Lintas Terhadap Kapasitas Jalan Di Pinggiran Kota Pontianak (Kasus Jalan Sungai Raya Dalam),” J. Mhs. Tek. Sipil Univ. Tanjungpura, vol. 4, no. 4, pp. 1-7, 2017.

[3] A. D. Limantara, A. I. Candra, and S. W. Mudjanarko, "Manajemen Data Lalu Lintas Kendaraan Berbasis Sistem Internet Cerdas Ujicoba Implementasi Di Laboratorium Universitas Kadiri,” 2017.

[4] R. H. Lalenoh, T. K. Sendow, and F. Jansen, “Analisa Kapasitas Ruas Jalan Sam Ratulangi Dengan Metode Mkji 1997 Dan Pkji 2014," J. Sipil Statik, vol. 3, no. 11, pp. 737-746, 2015.

[5] A. Di and K. Surakarta, "KINERJA ANALISIS DAMPAK LALU LINTAS," 2015.

[6] S. Awiyaningsih, H. Moetriono, and S. W. Mudjanarko, "ANALISIS DAMPAK LALU LINTAS PEMBANGUNAN MALL LAGOON AVENUE SUNGKONO TERHADAP KINERJA SIMPANG DI JALAN MAYJEND SUNGKONO - HR MUHAMMAD SURABAYA,” Tek. Eng. Sains J., vol. 2, no. 2, pp. 131-134, 2018.

[7] A. Y. Nurkafi, S. Winarto, and A. I. Candra, "ANALISA KINERJA SIMPANG TAK BERSINYAL JALAN SIMPANG BRANGGAHAN NGADILUWIH KABUPATEN 
KEDIRI,”Jurmateks, vol. 2, no. 1, pp. 164-178, 2019.

[8] E. H. Sunyoto, A. Ridwan, and S. Winarto, "MANAJEMEN REKAYASA LALU LINTAS PENGEMBANGAN WISATA KAMPUNG COKLAT," Jurmateks, vol. 2, no. 1, pp. 29-38, 2019.

[9] M. Atho 'ur Rohman, D. Kartikasari, K. Kunci, and : Kemacetan, "ANALISA KEMACETAN LALU LINTAS PADA PASAR TRADISIONAL DI RUAS JALAN SEKARAN-MADURAN," J. CIVILA, vol. 1, no. 2, pp. 1-6, 2016.

[10] R. Yuwono, Y. C. Sp, and L. D. K, "STUDY ANALISA VOLUME KENDARAAN PADA SIMPANG BERSINYAL DI PEREMPATAN ALUN ALUN KOTA KEDIRI,” Jurmateks, vol. 1, no. 1, pp. 101-111, 2018.

[11] E. Kusnandar, "Manual Kapasitas Jalan Indonesia 1997,” J. Jalan dan Jemb., vol. 26, no. 2, pp. 1-11, 2009.

[12] E. Gardjito, "STUDY PERENCANAAN GEOMETRIK, PERKERASAN JALAN DAN PERENCANAAN ANGGARAN BIAYA PADA JALAN RAYA KALIDAWIR-Ds. NGUBALAN Kec. KALIDAWIR,” UKaRsT, vol. 1, no. 2, p. 11, 2017.

[13] S. Awiyaningsih, H. Moetriono, and D. T. Sipil, "ANALISIS DAMPAK LALU LINTAS AKIBAT PEMBANGUNAN MALL LAGOON AVENUE SUNGKONO TERHADAP KINERJA SIMPANG DI JL MAYJEND SUNGKONO - HR MUHAMMAD SURABAYA," Tek. Eng. Sains J., vol. 2, no. 2, pp. 131-134, 2018.

[14] K. Universitas, S. A. M. Ratulangi, B. F. Sompie, J. A. Timboeleng, D. Pascasarjana, and U. S. Ratulangi, “Analisis dampak lalu lintas (andalalin) kawasan kampus universitas sam ratulangi," vol. 3, no. 2, pp. 133-143, 2013.

[15] A. D. Limantara, S. Winarto, and S. W. Mudjanarko, "SISTEM PAKAR PEMILIHAN MODEL PERBAIKAN PERKERASAN LENTURBERDASARKAN INDEKS KONDISI PERKERASAN ( PCI )," no. November, pp. 1-2, 2017.

[16] Anonim, Manual Kapasitas Jalan Indonesia. Jakarta, 1997.

[17] A. I. Candra, "STUDI KASUS STABILITAS STRUKTUR TANAH LEMPUNG PADA JALAN TOTOK KEROT KEDIRI MENGGUNAKAN LIMBAH KERTAS," UKaRsT, 2018, doi: 10.30737/ukarst.v2i2.255.

[18] S. W. Suntoyo Edi, Ahmad Ridwan, "Manajemen Rekayasa Lalu Lintas Pengembangan Wisata Kampung Coklat,” pp. 23-32, 2017.

[19] R. J. Salter, Highway Traffic Analysis and Design, Second Edi. London, 1989.

[20] Sukirman, "Page 1," p. 1999, 1999.

[21] Abubakar, "Pedoman Perencanaan Dan Pengoperasian Fasilitas Parkir," p. 1998, 1998. 